\title{
"A Comparative Study on Balance and Flexibility between National Level Artistic Gymnasts and National Level Dancer Girls Under 18-22 Years"
}

\author{
${ }^{1}$ Kuntal Majumder (M. Phil), ${ }^{2}$ Sonali Saha (M.P. Ed) ${ }^{3}$ Goutam Ghosh (M.P. Ed), \\ ${ }^{4}$ Himanshu Kayal (M. Phil) \\ ${ }^{I}$ Deptt, Of Physical Education (Sunrise University) R.A \\ ${ }^{2,3}$ Deptt. Of Physical Education (University Of Kalyani) W.B \\ ${ }^{4}$ Deptt. Of Physical Education.(Jodhpur National University) R.A
}

\begin{abstract}
The Main Purpose Of The Study Or Investigation Is To Find Out The Balance And Flexibility Between National Level Artistic Gymnast And National Level Dancer For Girls Under 18 To 22 Years. Total 60 Subjects Of 18-22 Years Age Group Were Taken As Subject And Equally Divided At Random Into Two Different Treatment Groups Viz, Gymnastics And Dance From National Level Competition And Various Dance Academy. The Measurement Of Balance And Flexibility Was Taken Into Account As A Criterion Measures. The Researcher Applied The Following Tests; Modified Storks Stand Test To Measure Static Balance And Modified Standing - Bending Reach Rating Test To Measure Hamstring Muscles Flexibility. From The Result It Is Found-National Artistic Gymnast Is Superior In Both Balance And Flexibility To A National Dancer. Besides, A Non-Significant Correlation Has Been Found Between - A) Height And Balance, B) Height And Flexibility, C) Weight And Balance, And D) Weight And Flexibility In National Artistic Gymnast And National Dancer.
\end{abstract}

Key Words: Girls, Gymnastics, Dance, Balance, Flexibility, National Level Artistic Gymnast, National Level Dancer.

\section{Introduction}

The Modern Age Is The Age Of Advancement And Technology Enhancing The Progress Of Mankind In Various Ways. Yet In This Mechanical Age People Tend To Look Back To Some Past Aspect Which Used To Enliven The 'Spirit' Of A Person. Dance Is Such An Aspect Of Our Life - An Art Form Which Enlivens The Body And Spirit Thereby Involving Movements Of The Body Often Rhythmical And To Music. Dance Is A Part And Parcel Of Our Culture And Tradition, An Outlet Of Our Emotions And A Medium Through Which We Become Vis-A-Vis Of Our Own Real Self. Oxford Dictionary Has Tried To Give A Proper Definition Of The Dance Form - "To Move With Measured Steps, Or To A Musical Accompaniment To Go Through, Either Alone Or In Company With Others, With A Regulated Succession Of Movements (Commonly) To The Sound Of Music; To Trip Or Leap Rhythmically. A Series Of Steps And Movements That Match The Speed And Rhythm Of A Piece Of Music".

Besides Dancing, Gymnastics Also Acts As A Medium Of Enrichment Of Our Body And Spirit. It Is A Sport Involving Performance Of Exercises Requiring Physical Strength, Flexibility, Power, Agility, Coordination, Grace, Balance And Control. Artistic Gymnastics Is Usually Decided Into Men's And Women's Gymnastics.

Now Both 'Dance' And 'Gymnastic' Involves 'Balance' And 'Flexibility' The Two Main Aspects Which Add A Completeness To Both. Before Arriving At Our Main Purpose, Let Me Provide A Brief Information About Balance And Flexibility In Some Joints That Can Be Increased To A Certain Degree By Exercise Including Stretching. "Balance On The Other Hand Is The Ability To Maintain The Equilibrium, An Even Distribution Of Weight Enabling Someone Or Something To Remain Upright And Steady" (Oxford Dictionary). The Two Types Of Balance Which Are In Common Use In Physical Education Are Tests Of Static Balance And Tests Of Dynamic Balance Which Further Depends Upon The Function Of The Mechanism In The Semicolon Canals.

The Main Purpose Of Our Research Work Is To Show A Comparative Study Of The Superiority Of 'Balance' And 'Flexibility' Between National Level Artistic Gymnasts And National Level Dancers Girls Under (18-22) Years Thereby Attempting To Find A Correlation Through Statistical Method.

\section{Purpose Of The Study}

The Study May Help To Understand The Balance And Flexibility Of National Level Artistic Gymnasts And National Level Dancers. Further It Will Help To Find Out The Superiority, If Any, Between Them In Balance And Flexibility. 
“A Comparative Study on Balance and Flexibility between National Level Artistic Gymnasts ...

\section{Statement Of The Problem}

The Research Project Is Concerned With Finding Out The Comparative Relation Between The Balance And Flexibility Of National Level Artistic Gymnasts And National Level Dancers.

\section{Limitation Of The Study}

1. The Equipment Used For Balance And Flexibility Measurement Was Provided By The Department Of Physical Education, Barkatullah Viswavidyalaya And University Of Kalyani.

2. Time Was Not Sufficient To Include More Subjects For This Project.

3. The Balance Was Measured Only By Stork Stand Test And The Flexibility Was Measured Only By Standing - Bending Reach Rating Test That Due To Lack Of Sophisticated Equipment.

\section{Delimitation of the Study}

1. 30 Female National Level Artistic Gymnasts And 30 Female National Level Dancers Were Selected For This Study.

2. The Age Groups Of The Subjects Were Between 18-22 Years.

3. The Study Was Confined In National Level Competition And Various Dance Academy.

4. Only Balance And Flexibility Of The Subject Was Measured.

5. Balance And Flexibility Were Measured By Indirect Method Of Measurement.

\section{Methodology}

The Main Purpose Of The Investigation Was To Find Out The Difference On Flexibility And Balance Between National Level Artistic Gymnast And National Level Dancer Girls Under 18-22 Years.

Total 60 Subjects Were Taken As The Subjects. Among Them 30 Student Were Participated In National Level Competition And 30 Students Were National Level Dancer.

The Measurement Of Abilities Such As Static Balance And Flexibility Were Taken Into Account As Criterion Measures. The Researcher Applied The Following Tests: Stork Stand Test And Standing- Bending Reach Rating Test.

\section{Result And Discussion}

In This Chapter The Collected Data That Have Been Presented Calculates Values For Different Parameters Which Have Been Also Included In This Chapter.

Table - 1 Mean \& S.D Of Age Height And Weight For National Level Gymnast And National Level Dancer Girls.

\begin{tabular}{|c|c|c|c|c|}
\hline Group & & Age & Height & Weight \\
\hline \multirow{3}{*}{ Gymnast } & & (Yrs.) & (C.M) & (K.G) \\
\cline { 2 - 5 } & Mean & 19.833 & 151.933 & 48.233 \\
\cline { 2 - 5 } & S.D & \pm 1.55 & \pm 4.54 & \pm 3.893 \\
\hline \multirow{3}{*}{ Dancer } & Mean & 19.63 & 152.066 & 50.73 \\
\cline { 2 - 5 } & S.D & \pm 1.687 & \pm 4.548 & \pm 3.04 \\
\hline
\end{tabular}

From The Table- 1 It Is Observed That The National Level Gymnasts' Mean Score Of Age Was 19.833 And S.D \pm 1.55. The National Level Gymnasts' Mean Score Of Height Was 151.933 And S.D \pm 4.54 ; The National Level Gymnasts' Mean Score Of Weight Was 48.233 And S.D \pm 3.893 .

The National Level Dancers' Mean Score Of Age Was 19.63 And SD \pm 1.687 ; The National Level Dancers' Mean Score Of Height Was 152.066 And S.D \pm 4.548. The National Level Dancers' Mean Score Of Weight Was 50.73 And S.D \pm 3.04 .

Table - 2 Mean And S.D Of Balance And Flexibility Of National Level Gymnast And National Level Dancer.

\begin{tabular}{|c|c|c|c|}
\hline Group & & Balance & Flexibility \\
\hline \multirow{3}{*}{ Gymnast } & Mean & 45.666 & 20 \\
\cline { 2 - 4 } & S.D & \pm 11.945 & \pm 4.45 \\
\hline \multirow{2}{*}{ Dancer } & Mean & 41.33 & 19.57 \\
\cline { 2 - 4 } & S.D & \pm 10.0477 & \pm 4.7936 \\
\hline
\end{tabular}

From Table - 2 It Is Observed That The National Gymnast's Mean Score Of Balance Was 45.666 And S.D \pm 11.945 . The National Gymnasts' Mean Score Of Flexibility Was 20 And S.D \pm 4.45 . 
The National Dancers' Mean Score Of Balance Was 41.33 And S.D \pm 10.0477 ; The Nation Dancers' Mean Score Of Flexibility Was 19.57 And S.D \pm 4.7936.

Table - 3 ' $\mathrm{T}$ ' Value Of National Gymnast And National Dancer In Respect Of Balance -

\begin{tabular}{|c|c|c|c|c|}
\hline Group & Mean & S.D & 'T' Value & Remarks. \\
\cline { 1 - 3 } National Gymnast & 45.666 & \pm 11.945 & & \multirow{2}{*}{ Not Significant } \\
\cline { 1 - 3 } National Dancer & 41.33 & \pm 10.0477 & \\
\hline
\end{tabular}

Where $\mathrm{Df}=58$

$* \mathrm{~T}=2.00$ At 0.05 Level

$* * \mathrm{~T}=2.66$ At 0.01 Level

From The Above Table It Is Observed That Balance Of National Gymnast's Was Better Than National Dancer's And It Was Not Significant At 0.05 Level.

Table - 4 'T' Value Of National Gymnast And National Dancer In Respect Of Flexibility.

\begin{tabular}{|c|c|c|c|c|}
\hline Group & Mean & S.D & 'T' Value & Remarks. \\
\cline { 1 - 3 } Gymnast & 20 & \pm 4.45 & \multirow{2}{*}{0.35} & Not Significant \\
\hline Dancer & 19.57 & \pm 4.7936 & & \\
\hline
\end{tabular}

Where Df $=38$

$$
\begin{aligned}
& * \mathrm{~T}=2.00 \text { At } 0.05 \text { Level. } \\
& * * \mathrm{~T}=2.66 \text { At } 0.01 \text { Level. }
\end{aligned}
$$

From The Above Table It Is Observed That Flexibility Of National Gymnast's Was Better Than National Dancer's And It Was Not Significant At 0.01 Level.

Table - 5 Correlation Of Height, Weight, Balance And Flexibility Of National Artistic Gymnast And National

\begin{tabular}{|c|c|c|c|c|}
\hline \multicolumn{5}{|c|}{ Dancer. } \\
\hline SL. No. & Parameters & Group & 'R' Value & Interpretation \\
\hline 01 & Height \& Balance & National Artistic Gymnast & 0.0747 & Non - Significant \\
\hline 02 & Weight \& Balance & National Artistic Gymnast & 0.0508 & Non - Significant \\
\hline 03 & Height \& Flexibility & National Artistic Gymnast & 0.2918 & Non - Significant \\
\hline 04 & Weight \& Flexibility & National Artistic Gymnast & 0.0808 & Non - Significant \\
\hline 05 & Height \& Balance & National Dancer & 0.2106 & Non - Significant \\
\hline 06 & Weight \& Balance & National Dancer & 0.0843 & Non - Significant \\
\hline 07 & Height \& Flexibility & National Dancer & 0.1165 & Non - Significant \\
\hline 08 & Weight \& Flexibility & National Dancer & 0.2059 & Non - Significant \\
\hline
\end{tabular}

Where, Df $=28$

$$
\begin{aligned}
& * \mathrm{R}=.361 \text { At } 0.05 \text { Level } \\
& * * \mathrm{R}=.463 \text { At } 0.01 \text { Level }
\end{aligned}
$$

It Was Observed From Table -5 That Height Of National Gymnast Was Not Correlated $(\mathrm{R}=0.0747)$ With Balance. Weight Was Not Correlated $(\mathrm{R}=0.0508)$ With Balance. Height Was Not Correlated $(\mathrm{R}=$ 0.2918) With Flexibility. Weight Was Not Correlated $(\mathrm{R}=0.0808)$ With Flexibility.

That Height Of National Dancer Was Not Correlated $(\mathrm{R}=0.2106)$ With Balance. Weight Was Not Correlated $(\mathrm{R}=0.0843)$ With Balance. Height Was Not Correlated $(\mathrm{R}=0.1165)$ With Flexibility. Weight Was Not Correlated $(\mathrm{R}=0.2059)$ With Flexibility.

\section{Conclusion}

Thus, On The Basis Of An Analytical Estimate Of The Results And Within The Limited Scope Of The Study, The Following Conclusion Could Be Made That A National Artistic Gymnast Is Superior In Both Balance And Flexibility To A National Dancer.

Besides, A Non-Significant Correlation Has Been Found Between - A) Height And Balance, B) Height And Flexibility, C) Weight And Balance, D) Weight And Flexibility - In National Artistic Gymnast And National Dancer.

Hence A Gymnast Provides A Satisfied Result Than A Dancer, When The Matter Of Flexibility Is Concerned. Yet In Spite Of A Non-Significant Correlation Between The Two, A Vast Difference In Points Can Be Traced. Likewise Differences Are Visible In Other Cases Too. Thus, Our Research Regarding This 
Comparative Study Can Be Said To Have Reached A Significant Conclusion Thereby Providing Us With A Report Which Is Both Satisfactory \& Acceptable To The Observer.

\section{Reference}

[1]. Brown, William M., Lee Cronk, Amy Jacobson, Keith Grochow, C.Karen, Liv, Zoranpopovic, And Robert Trivers. 2005. Nature$438: 1148-1150$

[2]. Fredrik Ullen, Lea Forsman, Orjan Blom, Anke Karabanovoch Guy Madison. Intelligence And Variability In A Simple Timing Task Share Neural Substrates In The Prefrontal White Matter. The Journal Of Neuroscience, 16 April 2008.

[3]. Edward L.Fox And Donald K. Mathews "The Physiological Basis Of Physical Education And Atheletics". Saunders College Publishing, Holtsaunders Japan. Iiird Edn. P-167.

[4]. C.A. Baucher And D.A. Wllest "Foundation Of Physical Education And Sports" Times Mirror / College Publishing (10 Th Edn) 1987.

[5]. Jhnson, Barry.L, And Nelson, Jack K. "Practical Measurement For Evalution In Physical Education." Surjeet Publication : Delhi 1982.

[6]. David H. Clarke And H. Harrison Clarke, Research Process In Physical Education Recreation And Health, New Jerry : Prantice Hall, Inc, 1970 P- 204.

[7]. Barrow, H.M And MC Gee ; A Practical Approach To Measurement In Physical Education, Philadelphia : Lea \& Fbiger, Third Edition, 1979 .

[8]. Mongal S.K.; Statistic And Psychology And Education, New Delhi : Tata Mc Grow - Hill Publishing Company Limited, 1987.

[9]. Verma J.P : A Text Book On Sports Statistics ; 7/26, Ground Floor, Ansari Road, Darya Ganj, New Delhi - 110002.

[10]. Garret, E.Henry And Woodworth, R.S. Statistic Psychology And Education, Delhi: M/S Paragon International Publishers 1961.

\section{Web Sources:}

Http://En.Wikipedia.Org

Http://Www.Wiki.Answers.Com

Http://Www. Dance.About.Com

Http://Www.Phecanda.Ca/Programs/Dance

Http://Www.Livestrong.Com

$\mathrm{Http}: / /$ Www.Wisegeek.Org

Http://Www.Answers. Yahoo.Com 